\title{
Geochemical and mineralogical evidences for evolved alkaline mamatism from pyroxene-hosted melt inclusions
}

\author{
INKYEONG MOON ${ }^{1}$, JONGUK KIM ${ }^{1}$, HYUNWOO LEE ${ }^{2}$, \\ DONGHOON SEOUNG ${ }^{3}$, JiHYE OH ${ }^{1}$, CHANG HWAN KIM ${ }^{4}$, \\ CHAN HONG PARK ${ }^{4}$, INSUNG LEE ${ }^{2}$ \\ ${ }^{1}$ Deep-sea and Seabed Mineral Resources Research Center, \\ Korea Institute of Ocean Science and Technology, Busan, \\ Republic of Korea \\ ${ }^{2}$ School of Earth and Environmental Sciences, Seoul \\ National University, Seoul, Republic of Korea \\ ${ }^{3}$ Faculty of Earth Systems and Environmental Sciences, \\ Chonnam National University, Gwangju, Republic of \\ Korea \\ ${ }^{4}$ East Sea Research Institute, Korea Institute of Ocean \\ Science and Technology, Uljin, Republic of Korea
}

Dokdo and Ulleung Islands in South Korea are a place of intraplate multi-stage volcanism and have complicated geologic setting. Geochemical study for volcanic rocks has been widely studied in terms of magma composition, eruption age and volumes, but the deep magmatic system of Dokdo and Ulleung Islands are still highly arguable.

Melt inclusions provide opportunity to depict the the physico-chemical evolution of magmatic systems, mantle composition, trapping temperature, cooling rate, and volatile contents. Hence, we report the first results of mineral chemistry of daughter minerals preserved in melt inclusions within clinopyroxene phenocrysts in trachybasalt, trachyandesite, and trachyte using in situ Raman spectroscopy, SEM, and EPMA technique. To summarized the results, the pyroxene-hosted melt inclusions are commonly composed of amphibole (hornblende \pm grunerite) \pm vesicles \pm Ti-rich magnetite. Especially, the magnetite contains relatively high $\mathrm{TiO}_{2}$ (average of 8.04 wt.\%) concentrations, which indicative of potential evidences of exsistence of Fe-Ti melts under oxidized condition. In addition, the euhderal magnetite might have been associated with high post-entrapment temperature (approximately $1150{ }^{\circ} \mathrm{C}$ ) of melt inclusions in Dokdo and Ulleung Islands. Therefore, we concluded that Dokdo and Ulleung Islands volcanoes were originated by $\mathrm{Fe}-\mathrm{Ti}$ rich magma under high temperature and oxidized conditions. 